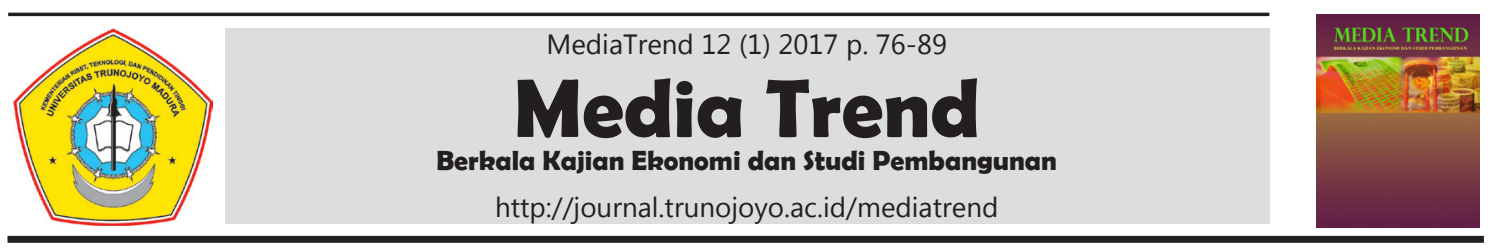

\title{
Tingkat Partisipasi Angkatan Kerja (TPAK) Perempuan Antar Kabupaten di Provinsi Riau
}

\author{
Muhammad Hidayat ${ }^{1, *}$, Sutrisno ${ }^{2}$, Muhammad Fikry Hadi ${ }^{3}$ \\ 1,2 University of Muhammadiyah Riau, Pekanbaru, Indonesia
}

\section{Informasi Artikel \\ Sejarah artikel: \\ Diterima Februari 2017 \\ Disetujui Maret 2017 \\ Dipublikasikan Maret 2017}

\section{Keywords:}

Care of the Household,

Education,

LFPR of female,

Panel Data Regression

\begin{abstract}
A BS TRACT
This study aims to analyze the trend of labor force participation rate of women district in Riau Province, identify and analyze the factors that affect labor force participation rate of female among the districts in the province of Riau. The analytical tool used in the form of panel data regression analysis to determine the influence of independent variables on the dependent variable that includes the number of people who take care of the household, the number of school-age population and education of the labor force participation rate of female. Based on the results of data processing can be concluded: Districts with the highest labor force participation rate is the District Rokan Hulu followed by the District of Bengkalis and Pelalawan District. While the district the lowest labor force participation rate Meranti-Islands district. The Population taking care of the household and school-age significantly influences the Labor Force Participation Rate of female, while education does not affect the Labor Force Participation Rates of femaleinter-districts in Riau province.
\end{abstract}




\section{Pendahuluan}

Pembangunan ekonomi daerah merupakan suatu proses yang mencakup pembentukan institusi baru, pembangunan industri alternatif, perbaikan kapasitas tenaga kerja yang ada untuk menghasilkan produk dan jasa yang lebih baik, identifikasi pasar-pasar baru, dan pengembangan perusahaan-perusahaan baru. Masalah pokok dalam pembangunan daerah berada pada penekanan terhadap kebijakan-kebijakan pembangunan yang berdasarkan pada kekhasan daerah yang bersangkutan (endogenous development) dengan menggunakan potensi sumberdaya manusia, kelembagaan, dan sumberdaya fisik secara lokal (daerah). Sehingga kita perlu melakukan pengambilan inisiatif-inisiatif yang berasal dari daerah tersebut dalam proses pembangunan untuk menciptakan kesempatan kerja baru dan merangsang kegiatan ekonomi.

Negara berkembang seperti Indonesia berpenduduk besar yang menjadi salah satu masalah utama adalah pengangguran struktural yang sangat besar. Masalah ini disebabkan karena struktur ekonomi yang ada belum mampu menciptakan kesempatan kerja yang sesuai dan dalam jumlah yang cukup untuk menyerap angkatan kerja yang ada. Agar mencapai keadaan yang seimbang maka seyogyanya mereka semua dapat tertampung dalam suatu perkerjaan yang cocok dengan keterampilan mereka. Ini membawa konsekuensi bahwa perekonomian sebaiknya harus selalu menyediakan lapangan pekerjaan bagi angkatan kerja yang baru.

Masalah penduduk tidak terlepas dengan masalah ketenagakerjaan. Suatu proses pembangunan peran serta tenaga kerja sangat menentukan berlangsungnya pembangunan disuatu negara. Tenaga kerja sebagai salah satu faktor ekonomi memiliki peran yang vital, biasa dikatakan bahwa tenaga kerja memberdayakan dan mengaplikasikan faktor-faktor lain untuk mencapai tujuan yang direncanakan. Tenaga kerja dalam hal ini merupakan orang atau manusia yang bekerja baik secara individu maupun kelompok dengan menggunakan kemampuan yang dimilikinya untuk mencapai hasil usaha yang maksimal. Tenaga kerja dalam hal ini adalah laki-laki dan perempuan yang termasuk dalam golongan tenaga kerja.

Jumlah penduduk yang tinggi menjadi masalah dibidang ketenagakerjaan khususnya penciptaan dan perluasan lapangan kerja. Untuk itu perlu adanya lapangan kerja baru yang menyerap angkatan kerja yang tersedia dan perlunya pola pendidikan untuk meningkatkan produktivitas tenaga kerja, lewat balai latihan dan pendidikan baik bersifat formal maupun informal.

Berdasarkan hasil sensus penduduk 2010 menunjukan jumlah penduduk Provinsi Riau sebesar 5.538.367 jiwa dengan laju pertumbuhan penduduk Provinsi Riau sebesar 3,59\%. Jumlah penduduk yang besar dan laju pertumbuhan yang tinggi ini telah mengantarkan Provinsi Riau pada posisi ke-10 sebagai provinsi dengan penduduk terbesar di Indonesia dan posisi ke 4 di Sumatra. Setiap tahunnya penduduk Riau selalu bertambah pada tahun 2014 penduduk Riau berjumlah 6.188.400 jiwa yang terdiri dari 3.178.400 jiwa penduduk laki-laki dan 3.010.000 jiwa penduduk perempuan. Jumlah penduduk Provinsi Riau setiap tahunnya semakin bertambah. Pada tahun 2012 jumlah penduduk Provinsi Riau sebesar 5.879.109 jiwa terdiri dari laki-laki 3.021.494 jiwa dengan TPAK sebesar $84,04 \%$ dan perempuan 2.857.615 jiwa dengan TPAK sebesar 40,41\%. Tahun 2013 jumlah penduduk sebesar 6.033.268 jiwa terdiri dari lakilaki 3.099.760 jiwa dengan TPAK sebesar $83,27 \%$ dan perempuan 2.933.508 jiwa TPAK sebesar $42,73 \%$. Pada tahun 2014 jumlah penduduk Provinsi Riau sebesar 6.188.442 jiwa terdiri dari lakilaki 3.178.486 jiwa dengan TPAK sebesar 
$83,87 \%$ dan perempuan 3.009.956 jiwa dengan TPAK sebesar 42,63\% (Badan Pusat Statistik Riau, 2015).

Kabupaten dengan jumlah penduduk terbanyak pada tahun 2012 di Provinsi Riau adalah Kabupaten Kampar dengan jumlah penduduk sebesar 773.171 jiwa terdiri dari laki-laki 397.107 jiwa dengan TPAK sebesar $85,70 \%$ dan perempuan 376.064 jiwa dengan TPAK sebesar $38,60 \%$, disusul oleh Kabupaten Indragiri Hilir dengan jumlah penduduk sebesar 694.614 jiwa terdiri dari laki - laki 356.791 jiwa dengan TPAK sebesar $84.00 \%$ dan perempuan 337.823 jiwa dengan TPAK $33,80 \%$, kabupaten dengan jumlah penduduk terendah adalah Kabupaten Kepulauan Meranti dengan jumlah penduduk sebesar 179.894 jiwa terdiri dari laki - laki 92.403 jiwa dengan TPAK sebesar 82,66\% dan perempuan 87.491 jiwa dengan TPAK 49,69\% (Badan Pusat Statistik Riau, 2015).

Pertumbuhan penduduk akan sangat mempengaruhi pertumbuhan angkatan kerja. Semakin besar jumlah pertumbuhan penduduk usia kerja, maka secara otomatis jumlah angkatan kerja akan bertambah. Semakin tinggi TPAK semakin baik, karena itu berarti partisipasi angkatan kerja semakin meningkat. Bila peningkatan angkatan kerja seiring dengan bertambahnya partisipasi penduduk yang bekerja, hal ini dapat berarti peningkatan TPAK diiringi dengan penurunan partisipasi penduduk yang bekerja ini pertanda bahwa pemicu tingginya TPAK adalah meningkatnya penduduk yang mencari pekerjaan dengan kata lain bertambahnya pengangguran (Mulyadi, 2003).

Oleh karena itu, tingkat partisipasi angkatan kerja merupakan salah satu faktor yang harus diperhitungkan dalam pembangunan nasional. Dalam kehidupan manusia selalu mengadakan bermacam-macam aktivitas. Salah satu aktivitas itu diwujudkan dalam gerakan-gerakan yang dinamakan kerja. Faktor pendorong penting yang menyebabkan manusia bekerja adanya kebutuhan yang harus dipenuhi. Aktivitas dalam kerja mengandung unsur suatu kegiatan sosial, menghasilkan sesuatu, dan pada akhirnya bertujuan untuk memenuhi kebutuhannya.

Ada beberapa karakteristik individu yang dapat mempengaruhi tingkat partisipasi angkatan kerja wanita yang menggambarkan sikap individu dalam kegiatan pasar tenaga kerja seperti pendidikan, usia penduduk, pendapatan dan lain-lain. Wanita memberikan sumbangan yang besar bagi kelangsungan perekonomian dan kesejahteraan rumah tangga dan masyarakat. Dengan adanya wanita bekerja akan dapat mengangkat kesejahteraan keluarga pekerja karena mendapat tambahan penghasilan dari hasil kerja wanita. Wanita pekerja umumya dianggap bukan sebagai pencari nafkah utama, walaupun penghasilan yang diperoleh sering sangat membantu bahkan merupakan penunjang utama ekonomi rumah tangga.

Berdasarkan latar belakang yang telah diuraikan diatas, maka yang menjadi pokok permasalahan dalam penulisan ini adalah tren dan faktor yang mempengaruhi tingkat partisipasi angkatan kerja perempuan antar kabupaten di Provinsi Riau.

\section{Hubungan Pendidikan dengan Tingkat Partisipasi Angkatan Kerja}

Pendidikan merupakan tujuan pembangunan yang mendasar yang mana pendidikan memainkan peran kunci dalam membentuk kemampuan sebuah negara dalam menyerap teknologi modern dan untuk mengembangkan kapasitas agar tercipta pertumbuhan serta pembangunan yang berkelanjutan. Variabel pendidikan dengan tingkat partisipasi angkatan kerja secara bersama-sama memiliki pengaruh yang signifikan (Todaro \& Smith, 2013).

Pendidikan mempengaruhi TPAK melalui dua jalur yaitu (Simanjuntak, 2001):

1. Proporsi penduduk yang sedang bersekolah umumnya lebih besar pada ke- 
lompok umur muda atau kelompok usia sekolah.

2. Semakin tinggi pendidikan seseorang, nilai waktunya menjadi tambah mahal. Orang yang menganggap waktunya mahal mereka cendrung untuk menggantikan waktu senggangnya untuk bekerja. Pengaruh ini terutama lebih nyata dikalangan wanita, wanita yang berpendidikan tinggi umumnya tidak tinggal dirumah untuk mengurus rumah tangga, akan tetapi masuk angkatan kerja.

\section{Hubungan Usia dengan Tingkat Partisi- pasi Angkatan Kerja}

Hubungan antara usia dengan tingkat partisipasi angkatan kerja yaitu umur tenaga kerja berkaitan langsung dengan kondisi fisik seorang tenaga kerja dalam melakukan kegiatanya. Semakin tua umur tenaga kerja maka kondisi fisiknya lebih rendah sehingga akan berpengaruh pada produktifitas tenaga kerja.

Tingkat partisipasi penduduk meningkat seirama dengan perkembangan umur Namun demikian pada umur tertentu tingkat partisipasi mencapai titik optimal kemudian menurun hingga titik terendah, terutama pada kelompok umur 60 tahun keatas. Berbagai variabel lain diperkirakan merupakan penyebab rendahnya tingkat partisipasi angkatan kerja.

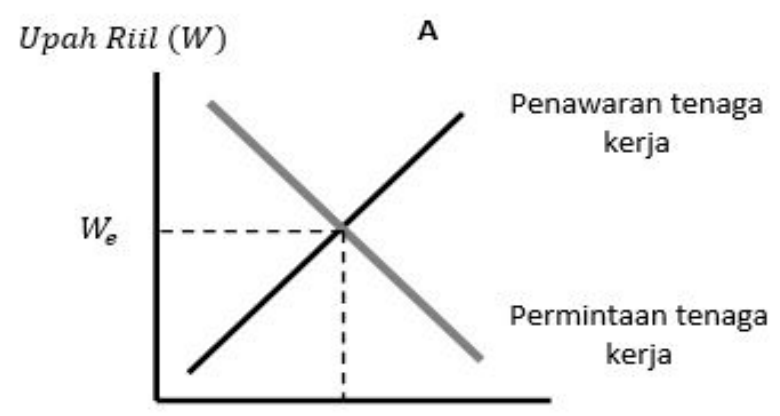

$N_{e} \quad$ Jumlah Tenaga Kerja $(N)$

Sumber: Adioetomo, Moertiningsih, \& Samosir, 2010

Gambar 1

Analisis Keseimbangan Permintaan dan Penawaran Tenaga Kerja

\section{Permintaan dan Penawaran Tenaga Kerja}

Salah satu masalah yang biasa muncul dalam bidang angkatan kerja adalah ketidak seimbangan akan permintaan tenaga kerja (demand for labor) dan penawaran tenaga kerja (supply of labor), pada suatu tingkatupah. Ketidaksimbangan

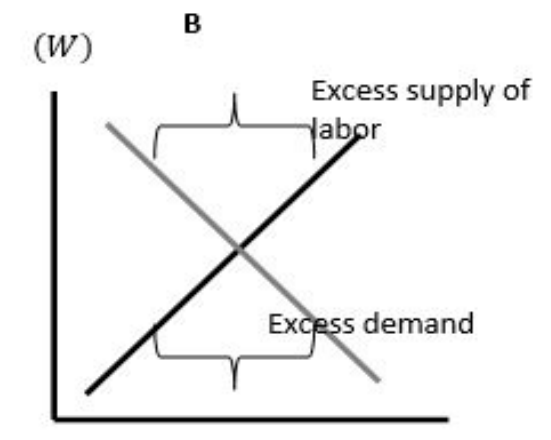

(N) 
tersebut penawaran yang lebih besar dari permintaan terhadap tenaga kerja (excess supply of labor) atau lebih besarnya permintaan dibandingkan penawaran tenaga kerja (excess demand for labor) dalam pasar tenaga kerja(Arfida, 2003).

Pada gambar 1 grafik $A$, menunjukkan keseimbangan jumlah orang yang menawarkan tenaganya untuk bekerja adalah sama dengan jumlah permintaan tenaga kerja yang diminta. Keseimbangan berada pada titik $\mathrm{E}$ atau perpotongan kurva demand dan supply. Dalam hal ini menunjukkan tidak ada orang yang menganggur. Grafik B menunjukkan ketidakseimbangan pasar tenaga kerja. Terlihat adanya kelebihan dari sisi demand dan supply tenaga kerja (Adioetomo, Moertiningsih, \& Samosir, 2010).

Untuk memberikan gambaran tentang variabel-variabel yang diteliti dalam penelitian, berikut ini dipaparkan hasilhasil penelitian terdahulu yang dipandang relevan dengan penelitian sebagai berikut:(Herlina, 2014) menjabarkan hasil penelitian tentang "Analisis Faktor-Faktor yang Mempengaruhi TPAK Perempuan di Kabupaten Siak" data dianalisis dengan mengunakan regresi linier berganda dengan hasil penelitian: Pendidikan dan upah mempunyai pengaruh terhadap TPAK. Sementara itu hasil penelitian (Cahaya, 2014) tentang "Faktor-Faktor yang Mempengaruhi Partisipasi Angkatan Kerja Wanita Muda dalam Kegiatan Ekonomi Kota Makasar" dengan menggunakan regresi linier berganda mengindikasikan variabel pendapatan, pendidikan, status sekolah dan lingkungan sosial berpengaruh positif dan signifikan terhadap jam kerja partisipasi angkatan kerja wanita muda dalam kegiatan ekonomi Kota Makassar.

Penelitian lain yang dilakukan dengan menggunakan regresi linier berganda menghasilkan bahwa Upah tidak berpengaruh signifikan terhadap TPAK laki-laki dan perempuan, usia penduduk ber- sekolah berpengaruh signifikan terhadap TPAK laki-laki dan perempuan, penduduk mengurus rumah tangga tidak signifikan terhadap TPAK laki-laki tetapi signifikan terhadap TPAK perempuan (Affandi, 2009). Selanjutnya, (Riyadi, 2001) dengan mengunakan regresi linier berganda memberikan hasil bahwa secara deskriptif umur, pendidikan, status sosial dan daerah asal sangat mempengaruhi TPAK perempuan.

\section{Metodologi Penelitian}

Penelitian ini menggunakan data sekunder runtun waktu (time series) periode tahun 2010-2014, yang diperoleh dari berbagai laporan dan kompilasi data serta bentuk publikasi lainnya, seperti dari Disnaker, Badan Pusat Statistik dan Badan Perencana Pembangunan Daerah Kabupaten yang ada di Provinsi Riau.

\section{Definisi Operasional Variabel}

1) Tingkat partisipasi angkatan kerja didefinisikan sebagai perbandingan antara angkatan kerja dengan jumlah seluruh penduduk usia kerja.

Secara matematis dapat dirumuskan sebagai berikut :

TPAK $=\frac{\text { Jumlah Angkatan Kerja }}{\text { Jumlah Penduduk Usia Kerja }} \times 100 \%$

2) Jumlah angkatan kerja dipengaruhi oleh jumlah penduduk yang bersekolah dan mengurus rumah tangga. Semakin banyak penduduk yang bersekolah dan mengurus rumah tangga, maka semakin sedikit jumlah penduduk yang tergolong angkatan kerja dan semakin rendah tingkat partisipasi angkatan kerja.

Secara matematis dapat dirumuskan sebagai berikut :

$$
M S=\frac{\text { Penduduk Usia Sekolah }}{\text { Jumlah Angkatan Kerja }} \times 100 \%
$$

3) Pendidikan merupakan suatu usaha yang dilakukan secara sadar dan terencana untuk mewujudkan suasana dan 
proses pembelajaran agar peserta didik secara aktif mampu mengembangkan potensi yang ada didalam dirinya untuk memiliki kekuatan spiritual keagamaan, kepribadian yang baik, pengendalian diri, berakhlak mulia, kecerdasan,dan keterampilan yang diperlukan oleh dirinya dan masyarakat (Undang-undang SISDIKNAS No. 20 tahun 2003, n.d.).

Secara matematis dapat dirumuskan sebagai berikut :

$$
\text { PDDK }=\frac{\text { Pendidikan Tertinggi }}{\text { Jumlah Angkatan kerja }} \times 100 \%
$$

\section{Analisis Faktor yang Mempengaruhi TPAK Perempuan}

Untuk menganalisis faktor-faktor yang mempengaruhi TPAK perempuan antar kabupaten di Provinsi Riau digunakan regresi data panel. Fungsi yang terbentuk menyerupai persamaan regresi dengan TPAK perempuan antar kabupaten diduga dipengaruhi oleh variabel penduduk mengurus rumah tangga (MRT), usia penduduk yang bersekolah (MS) dan pendidikan (PDDK) tiap kabupaten/ kota. Variabel-variabel yang memiliki nilai koefisien regresi terbesar, dianggap memiliki peranan penting dalam mempengaruhi naik turunnya TPAK perempuan di Provinsi Riau.

Adapun bentuk persamaan umumnya adalah :

$$
\mathrm{TPAK}=\{\mathrm{MRT}, \mathrm{MS}, \mathrm{PDDK}\}
$$

Persamaan linier model regresi data panel dapat dirumuskan dalam model berikut:

$$
\begin{aligned}
& \text { TPAK }_{\text {it }}=\alpha_{\text {it }}+\beta_{1} \mathrm{MRT}_{\text {it }}+\beta_{2} \mathrm{MS}_{\text {it }}+ \\
& \beta_{3} \mathrm{PDDK}_{\mathrm{it}}+\varepsilon_{\mathrm{it}}
\end{aligned}
$$

Keterangan: (1) TPAK= Tingkat Partisipasi Angkata Kerja (\%); (2) MRT= Mengurus Rumah Tangga (\%); (3) MS= Usia Masih Sekolah (\%); (4) PDDK= Pendidikan (\%); (5) $\mathrm{i}=$ Kabupaten Provinsi Riau; (6) $\mathrm{t}=$ Waktu (2010 - 2014); (7) $\alpha=$ Konstanta; (8) $\varepsilon=$ Error Term.

\section{Analisis Data Panel}

Data panel (panel pooled data) merupakan gabungan data cross section dan series. Dengan kata lain, data panel merupakan data dari beberapa individu sama yang diamati dalam kurun waktu tertentu. Jika kita memiliki $T$ periode waktu $(t=$ $1,2, \ldots, T)$ dan $N$ jumlah individu $(i=1,2, \ldots, N)$, maka dengan data panel kita akan memiliki total unit observasi sebanyak NT. Jika jumlah unit waktu sama untuk setiap individu, maka data disebut balanced panel. Jika sebaliknya, yakni jumlah unit waktu berbeda untuk setiap individu, maka disebut unbalanced panel. Dalam penelitian ini, digunakan data yang bersifat balanced panel. Oleh karena data diperoleh dari 10 kabupaten yang diamati dalam kurun waktu 5 tahun maka diperoleh 50 observasi. Penggunaan data panel pada dasarnya merupakan solusi atas ketidaktersediaan data time-series yang cukup panjang untuk kepentingan analisis ekonometrika.

Penggunaan data panel dalam regresi memiliki beberapa keuntungan, diantaranya; 1) Estimasi data panel dapat menunjukkan adanya heterogenitas dalam tiap individu. 2) Dengan data panel, data lebih informatif dan bervariasi, sehingga mengurangi kolinearitas antar variabel dan meningkatkan derajat kebebasan (degree of freedom), serta lebih efisien. 3) Studi data panel lebih memuaskan untuk menentukan perubahan dinamis dibandingkan dengan studi berulang dari cross-section. 4) Data panel mampu mendeteksi dan mengukur efek yang secara sederhana tidak dapat diukur oleh data time series atau cross-section. 5) Data panel membantu menganalisis perilaku yang lebih kompleks. 6) Data panel mampu meminimalkan bias yang dihasilkan oleh agregasi individu karena unit data yang banyak (Baltagi, 2005).

\section{Estimasi Regresi Data Panel}

Secara umum dengan menggunakan data panel kita akan menghasilkan 
intersep dan slope koefisien yang berbeda pada setiap perusahaan dan setiap periode waktu. Oleh karena itu, di dalam mengestimasi persamaan (2) akan sangat tergantung dari asumsi yang kita buat tentang intersep, koefisien slope dan variabel gangguannya. Ada beberapa kemungkinan yang akan muncul, yaitu (Gujarati, 2004): (a) Diasumsikan intersep dan slope adalah tetap sepanjang waktu dan individu (perusahaan) dan perbedaan intersep dan slope dijelaskan oleh variabel gangguan; (b) Diasumsikan slope adalah tetap tetapi intersep berbeda antar individu; (c) Diasumsikan slope tetap tetapi intersep berbeda baik antar waktu maupun antar individu; (d) Diasumsikan intersep dan slope berbeda antar individu; (e) Diasumsikan intersep dan slope berbeda antar waktu dan antar individu.

Dalam analisis model data panel terdapat tiga macam pendekatan yaitu Pooled Least Square (PLS), Model Efek Tetap (Fixed Effect Model), dan Model Efek Acak (Random Effect Model). Ketiga pendekatan pada model data panel akan dijelaskan berikut ini:

1) Pooled Least Square (PLS)

Metode pendekatan kuadrat terkecil ini pada dasarnya sama dengan metode ordinary least square (OLS) hanya saja data yang digunakan bukan data time series saja atau cross section saja tetapi merupakan data panel (campuran antara time series dan cross section). Sesuai dengan namanya yaitu pooled yang berarti dalam metode ini digunakan data panel dan least squares yang berarti metode ini meminimumkan jumlah error kuadrat. Meminimumkan error kuadrat dikarenakan error kuadrat kemungkinan besar jika dijumlahkan akan bernilai nol dan jika error hanya dijumlahkan saja tanpa dikuadratkan maka terjadi "ketidakadilan" karena nilai error yang besar dan yang kecil disamaratakan. PLS merupakan pendekatan yang sederhana, namun hasilnya tidak memadai karena setiap pengamatan diperlakukan seperti pengamatan yang berdiri sendiri.

\section{2) Fixed Effect Model (FEM)}

Masalah yang timbul pada penggunaan metode Pooled Least Square yaitu adanya asumsi bahwa intersep dan koefisien dari setiap variabel sama pada setiap Kabupaten yang diobservasi. Untuk memperhitungkan individualitas dari setiap unit cross-section dapat dilakukan dengan cara menjadikan intersep berbeda pada tiap kabupaten. Pada metode fixed effect ditambahkan variabel dummy untuk mengubah intersep, tetapi koefisienkoefisien lainnya tetap sama bagi setiap kabupaten yang diobservasi. Berdasarkan asumsi struktur matriks varians-kovarians residualnya, pada model fixed effects, ada 3 metode estimasi yang dapat digunakan, yakni: 1) Ordinary Least Square (OLS/ LSDV), jika struktur matriks varianskovarians residualnya diasumsikan bersifat homoskedastik dan tidak ada cross sectional correlation. 2) Weighted Least Square (WLS), jika struktur matriks varians-kovarians residualnya diasumsikan bersifat heteroskedastik dan tidak ada cross sectional correlation. 3) Seemingly Uncorrelated Regression (SUR), jika struktur matriks varians-kovarians residualnya diasumsikan bersifat heteroskedastik dan ada cross sectional correlation. 3) Random Effect Model (REM) Berbeda dengan fixed effects model, efek spesifik dari masing-masing individu $\alpha_{i}$ diperlakukan sebagai bagian dari komponen error yang bersifat acak dan tidak berkorelasi dengan variabel penjelas yang teramati $\left(\mathrm{X}_{\mathrm{it}}\right)$, model seperti ini dinamakan random effects model (REM). Model ini sering disebut juga dengan error component model (ECM). Metode OLS tidak bisa digunakan untuk mendapatkan estimator 
yang efisien bagi model random effects. Metode yang tepat untuk mengestimasi model random effects adalah Generalized Least Squares (GLS) dengan asumsi homokedastik dan tidak ada cross-sectional correlation.

\section{Pemilihan Model Dalam Pengolahan Data}

Secara formal, ada tiga prosedur pengujian yang akan digunakan, yaitu uji statistik $F$ yang digunakan untuk memilih antara model pooled least square atau fixed effects; uji Langrange Multiplier (LM) yang digunakan untuk memilih antara model pooled least square atau model random effects; dan uji Hausman yang digunakan untuk memilih antara model fixed effects atau model random effects (Gujarati, 2004).

\section{Pengujian Signifikansi Model Fixed Ef- fects}

Pengujian signifikansi model fixed effects dilakukan dengan uji statistik F. Uji $\mathrm{F}$ digunakan untuk mengetahui apakah teknik regresi data panel dengan fixed effects lebih baik dari model regresi pooled least square. Hipotesis null $(\mathrm{H} 0)$ yang digunakan adalah model pooled least square lebih baik, dengan kata lain tidak terdapat perbedaan antar individu (Widarjono, 2013).

\section{Pengujian Signifikansi Model Random Effects}

Untuk pengujian signifikansi model random effects dapat digunakan uji Langrange Multiplier (LM). Model ini didasarkan pada nilai residual dari model pooled least square. Hipotesis null $(\mathrm{H} 0)$ yang digunakan adalah bahwa varians dari efek spesifik individu ai sama dengan nol, dengan kata lain tidak terdapat adanya efek tidak teramati pada komponen error model random effects. Dengan kata lain model pooled least square lebih baik dari random effects model. LM akan mengi- kuti distribusi chi-square dengan derajat bebas (df) sebesar 1. Jika LM lebih besar dari chi-square pada tabel dengan signifikansi (alpha tertentu), maka hipotesis null akan ditolak, yang berarti model estimasi yang tepat untuk regresi data panel adalah model random effects daripada model pooled least square(Widarjono, 2013).

\section{Hausman Test.}

Uji Hausman adalah pengujian statistik sebagai dasar pertimbangan dalam memilih apakah menggunakan FEM atau REM. Uji Hausman dilakukan dengan hipotesis sebagai berikut: $\mathrm{H}_{0}$ : REM dan $\mathrm{H}_{1}$ : FEM. Sebagai dasar penolakan $\mathrm{H}_{0}$ maka digunakan Statistik Hausman dan membandingkannya dengan Chi-Square. Jika nilai $m$ hasil pengujian lebih besar dari $\mathrm{X}^{2}$-Tabel, atau nilai Hausman Test lebih besar dari taraf nyata, maka tidak cukup bukti untuk melakukan penerimaan terhadap $\mathrm{H}_{0}$. Sehingga model yang digunakan adalah fixed effect, demikian pula sebaliknya (Widarjono, 2013).

\section{Pengujian Hipotesis}

Sebelum dilakukan pengujian hipotesis (Uji F, Uji T, dan $\mathrm{R}^{2}$ ), maka terlebih dahulu model tersebut diuji agar memenuhi persyaratan BLUE (Best Linear Unbiased Estimator) yaitu menguji dengan uji asumsi klasik, yaitu uji autokerasi, uji multikolinearitas dan uji heteroskesdastositas (Widarjono, 2013).

\section{Hasil dan Pembahasan Hasil Analisis Ekonometrika Hausman Test}

Uji hausman bertujuan untuk memilih apakah menggunakan metode fixed effect atau random effect yang paling baik untuk digunakan. Dengan asumsi hipotesa $\mathrm{H}_{0}$ : merupakan metode random effect dan $\mathrm{H}_{1}$ : merupakan metode fixed effect. 
Tabel 1

Hasil Hausman Test

\begin{tabular}{|c|c|c|c|}
\hline Test Summary & Chi-Sq. Statistic & Chi-Sq. d.f. & Prob. \\
\hline Cross-section random & 9.064557 & 3 & 0.0284 \\
\hline \multicolumn{4}{|c|}{ Sumber: Data Olahan, 2016} \\
\hline \multicolumn{2}{|c|}{$\begin{array}{l}\text { Berdasarkan hasil analisis uji } \\
\text { Hausman di atas, didapatkan nilai chi- } \\
\text { square sebesar } 9,064557 \text { dengan proba- } \\
\text { bilitas }=0.0284<0,05 \text { maka keputusannya } \\
\text { adalah tolak } \mathrm{H}_{0} \text { dan } \mathrm{H}_{1} \text { terima. Sehingga } \\
\text { berdasarkan uji Hausman model yang te- } \\
\text { pat untuk menganalisis TPAK perempuan } \\
\text { diatas adalah model fixed effect dari pada }\end{array}$} & \multicolumn{2}{|c|}{$\begin{array}{l}\text { penduduk mengurus rumah tangga, usia } \\
\text { penduduk yang masih sekolah, dan pen- } \\
\text { didikan terhadap tingkat partisipasi angka- } \\
\text { tan kerja perempuan antar kabupaten di } \\
\text { Provinsi Riau digunakan analisis regresi } \\
\text { data panel dengan fixed effectmodel. Ber- } \\
\text { dasarkan hasil penelitian diperoleh garis } \\
\text { persamaan regresi sebagai berikut: }\end{array}$} \\
\hline
\end{tabular}

model random effect.

Tabel 2

Ringkasan Hasil Regresi Fixed Effect Model

\begin{tabular}{|c|c|c|c|}
\hline Variable & Coefficient & t-Statistic & Prob. \\
\hline $\mathrm{C}$ & 94.35975 & 33.80103 & 0.0000 \\
\hline MRT? & -1.021922 & -39.55712 & 0.0000 \\
\hline MS? & -0.996198 & -10.63403 & 0.0000 \\
\hline PDDK? & 0.060634 & 1.928959 & 0.0614 \\
\hline \multicolumn{4}{|l|}{ Fixed Effects (Cross) } \\
\hline KUANSING-C & 0.074044 & & \\
\hline INHIL $-\mathrm{C}$ & 0.122200 & & \\
\hline IINHU_C & -1.829383 & & \\
\hline PELALAWVAN $\mathrm{C}$ & 0.904049 & & \\
\hline SIAK-C & 0.460671 & & \\
\hline KAMPAR_C & -0.052381 & & \\
\hline ROHUL_C & 1.065427 & & \\
\hline _BENGKALIS-C & 1.010627 & & \\
\hline ROHIL $-\mathrm{C}$ & 0.138522 & & \\
\hline _MERANTI-C & -1.893776 & & \\
\hline R-squared & 0.973116 & & \\
\hline Adjusted R-squared & 0.964397 & & \\
\hline F-statistic & 111.6082 & & \\
\hline Prob(F-statistic) & 0.000000 & & \\
\hline Durbin-Watson stat & 2.216248 & & \\
\hline
\end{tabular}

\section{Fixed Effect Model}

Setelah dilakukan penyeleksian model dengan cara sebelumnya maka, untuk mengetahui besaran pengaruh jumlah
$\mathrm{TPAK}_{\text {it }}=94,35975-1,021922 \mathrm{MRT}-$ $0.996198 \mathrm{MS}+0,060634 \mathrm{PDDK}+\mu_{\mathrm{it}}$ 
Hasil regresi metode fixed effect menyatakan bahwa variabel pendidikan bertanda positif dan secara statistik tidak signifikan. Sementara variabel penduduk mengurus rumah tangga dan penduduk usia sekolah bertanda negatif dan secara statistik signifikan. Signifikasinya variabel dummy ini menunjukan bahwa intersep antara sepuluh Kabupaten tersebut berbeda. Dengan demikian model fixed effect mampu menjelaskan adanya perbedaan perilaku sepuluh Kabupaten tersebut.

\section{Analisis Persamaan Masing-masing Kabupaten di Provinsi Riau}

Berdasarkan tabel 2, didapatkan informasi nilai TPAK masing-masing kabupaten, yang mana apabila diasumsikan (Caterisparibus) bahwa variabel lain (MRT, MS, dan PDDK) bernilai nol, maka nilai TPAK kabupaten adalah 94,43\%, Kabupaten Indragiri Hilir adalah 94,48\%, Kabupaten Indragiri Hulu adalah 92,53\%, Kabupaten Pelalawan adalah 95,26\%, Kabupaten Siak adalah 94,82\%, Kabupaten Kampar adalah 94,30\%, Kabupaten Rokan Hulu adalah 95,42\%, Kabupaten Bengkalis adalah 95,37\%, Kabupaten Rokan Hilir adalah 94,50\%, Kabupaten Kepulauan Meranti adalah 92,47\%. Nilai TPAK tertinggi mengindikasikan bahwa kabupaten tersebut memiliki tenaga kerja perempuan yang banyak.

Berdasarkan hasil analisis diatas dapat disimpulkan Kabupaten dengan tingkat partisipasi angkatan kerja tertingi adalah Kabupaten Rokan Hulu sebesar 95,42\% disusul oleh Kabupaten Pelalawan sebesar 95,36\% dan Kabupaten Bengkalis sebesar $95,37 \%$ sedangkan kabupaten dengan tingkat partisipasi angkatan kerja terendah adalah Kabupaten Kepulauan meranti sebesar $92,46 \%$.

\section{Uji Statistik}

Hasil regresi fixed effect modelmenghasilkan nilai $R^{2}$ yaitu 0,973116 ini menujukan bahwa $97,31 \%$ jumlah pen- duduk mengurus rumah tangga, penduduk usiasekolah dan pendidikan mempengaruhi tingkat partisipasi angkatan kerja perempuan kabupaten di Provinsi Riau. Sementara itu nilai Adjusted $R$-squared yaitu sebesar 0.964397, yang mana nilai ini digunakan untuk membandingkan model apabila ada penambahan variabel bebas. Nilai Probabilitas dari F-statistik yaitu 0,000000 memberikan arti bahwa jumlah penduduk mengurus rumah tangga, penduduk usia sekolah dan pendidikan signifikan terhadap tingkat partisipasi angkatan kerja secara statistik. Nilai prob ( $t$-stat) yang kurang dari 0,05 dengan tingkat keyakinan $5 \%$, sehingga dengan tingkat keyakinan $5 \%$ variabel yang signifikan mempengaruhi tingkat parisipasi angkatan kerja adalah dan penduduk yang mengurus rumah tangga, penduduk usia sekolah dan pendidikan.

\section{Pengaruh Jumlah Penduduk Mengurus Rumah Tangga Terhadap TPAK Perem- puan}

Nilai koefisien regresi data panel TPAK perempuan adalah -1.021922 artinya apabila terjadi peningkatan perentase penduduk perempuan mengurus rumah tangga sebesar 1 satuan maka akan mengurangi tingkat partisipasi angkatan kerja perempuan sebesar $1,023 \%$. Nilai tstatistik -39,55712 dengan nilai probabilitas sebesar $0,0000<0,05$ tingkat signifikan. Dengan demikian dapat disimpulkan bahwa faktor jumlah penduduk perempuan mengurus rumah tangga berpengaruh secara signifikan terhadap turunnya TPAK perempuan.

Perbandingan persentase jumlah penduduk antar kabupaten yang mengurus rumah tangga mengalami perubahan tiap tahunnya. Pada tahun 2011 rata-rata penduduk perempuan yang mengurus rumah tangga mengalami penurunan kecuali Kabupaten Indragiri Hilir, Siak, Kepulauan Meranti mengalami peningkatan sebesar $43,41 \%, 43,39 \%$ dan $42,61 \%$. Tahun 
2012 penduduk mengurus rumah tangga mengalami peningkatan kecuali Kabupaten Bengkalis turun menjadi $41,32 \%$ serta Kepulauan Meranti turun dratis menjadi $29,62 \%$. Kabupaten Bengkalis mengalami peningkatan kembali penduduk mengurus rumah tangga pada tahun 2013 menjadi $43,13 \%$ dan Kepulauan Meranti mengikuti kenaikan penduduk mengurus rumah tangga menjadi $32,45 \%$. Pada tahun 2014 penduduk perempuan yang mengurus rumah tangga mengalami peningkatan seperti Kabupaten Kampar, Inhil, Rokan Hilir dan Rokan Hulu kecuali Kabupaten kepulauan meranti turun menjadi $21,65 \%$.

Menurut Simanjuntak (2001) semakin banyak anggota dalam tiap-tiap keluarga yang mengurus rumah tangga semakin kecil TPAK (pengaruh negatif). Hasil penelitian ini menunjukan bahwa hal ini sesuai dengan hasil penelitian dimana jumlah penduduk mengurus rumah tangga berpengaruh negatif terhadap TPAK perempuan. Selanjutnya hasil penelitian Affandi (2009) yang mengatakan jumlah penduduk perempuan usia kerja yang mengurus rumah tangga berpengaruh negatif terhadap tingkat partisipasi angkatan kerja dan sigifikan hal ini karena persentase penduduk perempuan yang mengurus rumah tangga jauh lebih besar dari pada laki-laki. Rumah tangga yaitu seseorang atau sekelompok orang yang mendiami sebagian atau seluruh bagunan, dan biasanya tinggal bersama serta makan dari satu dapur, yang dimaksud makan satu dapur adalah jika pengurusan kebutuhan sehari-hari dilakukan bersama-sama menjadi satu. Anggota rumah tangga adalah semua orang yang tinggal dalam satu rumah, baik yang berada pada waktu pencacahan maupun sementara tidak ada.

\section{Pengaruh Jumlah Penduduk Usia Sekolah Terhadap TPAK Perempuan}

Nilai koefisien regresi data panel TPAK perempuan adalah -0,996198 artinya apabila terjadi peningkatan perentase pen- duduk perempuan usia sekolah sebesar 1 satuan maka akan mengurangi tingkat partisipasi angkatan kerja perempuan sebesar $0,996 \%$. Nilai probabilitas lebih kecil dari tingkat keyakinan $(0,0000<0,05)$. Dengan demikian dapat disimpulkan bahwa faktor jumlah penduduk perempuan usia sekolah berpengaruh secara signifikan terhadap naik turunya tingkat partisipasi angkatan kerja perempuan.

Persentase usia penduduk yang masih bersekolah dari tahun 2010-2014 mengalami perbedaan setiap Kabupaten di Provinsi Riau serta setiap tahunnya masing-masing kabupaten mengalami kenaikan dan penurunan. Pada tahun 2011 kabupaten yang mangalami penurunan usia penduduk yang bersekolah adalah Kabupaten Kuantan singingi, Siak, Kampar, Rokan Hulu, bengkalis, Rokan Hilir, dan Kepulauan Meranti sementara itu Kabupaten Indragiri Hulu, Indragiri Hilir dan pelalawan mengalami peningkatan dari tahun 2010. Pada tahun 2014 usia penduduk yang masih sekolah mengalami peningkatan kecuali Kabupaten Kepulauan Meranti mengalami penurunan sebesar $5,17 \%$ dibandingkan pada tahun 2013 perempuan turun menjadi $5,95 \%$ pada tahun 2014 dibandingklan tahun 2013 sebesar 9,56\%. Hasil penelitian ini sejalan dengan hasil penelitian Affandi (2009) yang mengatakan jumlah penduduk perempuan pada usia kerja yang masih bersekolah secara parsial berpengaruh negatif terhadap tingkat partisipasi angkatan kerja perempuan.

Menurut Simanjuntak (2001) semakin besar jumlah penduduk yang bersekolah, semakin kecil TPAK (berpengaruh negatif). Hal ini sesuai dengan hasil penelitian dimana jumlah penduduk usia sekolah berpengaruh negatif terhadap TPAK perempuan.

Bersekolah merupakan salah satu kegiatan yang dilakukan oleh beberapa orang untuk membekali diri agar dapat melakukan sesuatu yang bisa bermanfaat bagi diri sendiri dan orang lain. Dengan 
bersekolah seseorang banyak mendapatkan ilmu dan pengetahuan sehingga dia mampu mengasah skill yang dimilikinya. Kemampuan yang dimiliki seseorang dapat bermanfaat apabila dia bisa melakukan untuk diri sendiri dan berguna bagi orang lain.

\section{Pengaruh Pendidikan Terhadap TPAK Perempuan}

Nilai koefisien regresi data panel TPAK perempuan adalah 0,060634 artinya apabila terjadi peningkatan perentase pendidikan sebesar 1 satuan maka akan menambah tingkat partisipasi angkatan kerja perempuan sebesar $0,061 \%$. Nilai probabilitas sebesar 0,0614 >0,05 tingkat signifikan menyatakan $\mathrm{H}_{0}$ diterima dan $\mathrm{H}_{1}$ ditolak, yang artinya pendidikan tidak berpengaruh secara signifikan terhadap tingkat partisipasi angkatan kerja perempuan. Apabila dilihat dengan tingkat signifikan 0,1 dengan tingkat keyakinan $90 \%$ maka hasil yang diperoleh adalah nilai probabilitas 0,0614 < 0,1 menyatakan $\mathrm{H}_{0}$ ditolak dan $\mathrm{H}_{1}$ diterima yang artinya pendidikan berpengaruh secara signifikan terhadap tingkat partisipasi angkatan kerja perempuan.

Setiap tahunnya pendidikan di kabupaten Provinsi Riau mengalami fluktuatif seperti pada tahun 2013 kabupaten dengan tingkat pendidikan tertinggi adalah Kabupaten Kepulauan Meranti pendidikan perempuan sebesar $37,22 \%$ dibandingkan dengan tahun 2014 Kabupaten Kepulauan Meranti turun menjadi $35,10 \%$. Pada tahun 2013 kabupaten dengan tingkat pendidikan terendah adalah Kabupaten Rokan Hulu sebesar $22,42 \%$ sementara pada tahun 2014 mengalami peningkatan menjadi $26,37 \%$. Meningkatnya pendidikan tertentu akan memperbaiki kualitas sumber daya manusia yang akan berdampak pada penggunaan modal fisik menjadi lebih efisien dan tenaga kerja akan menjadi lebih produktif. Dengan demikian, produktifitas baik modal fisik maupun tenaga kerja akan meningkat dan pada akhirnya akan meningkatkan pertumbuhan ekonomi dan kesenjangan pembangunan dapat menurun (Hidayat, 2014).

Menurut Simanjuntak (2001) Semakin tinggi pendidikan seseorang, nilai waktunya menjadi tambah mahal. Orang yang menganggap waktunya mahal mereka cendrung untuk menggantikan waktu senggangnya untuk bekerja. Pengaruh ini terutama lebih nyata dikalangan wanita, wanita yang berpendidikan tinggi umumnya tidak tinggal dirumah untuk mengurus rumah tangga, akan tetapi masuk dalam angkatan kerja berakibat semakin besar TPAK (berpengaruh positif). Hal ini sesuai dengan hasil penelitian dimana pendidikan berpengaruh positif terhadap TPAK perempuan.

\section{Penutup}

Berdasarkan hasil pembahasan mengenai analisis faktor-faktor yang mempengaruhi tingkat partisipasi angkatan kerja kabupaten di Provinsi Riau diperoleh kesimpulan sebagai berikut: (1) Tingkat partisipasi angkatan kerja perempuan dimasing-masing kabupaten di Provinsi Riau menunjukan bahwa perempuan lebih memilih bekerja dibandingkan mengurus rumah tangga dan melanjutkan sekolah serta pendidikannya. Karena masyarakat yang ada di Kabupaten terutama yang tinggal didaerah perkotaan lebih memilih bekerja agar dapat membantu keluarga. Kabupaten dengan tingkat partisipasi angkatan kerja tertinggi yaitu Kabupaten Rokan Hulu, Kabupaten Bengkalis dan Kabupaten Pelalawan. Sementara kabupaten tingkat partisipasi angkatan kerja terendah adalah Kabupaten Kepulauan Meranti; (2) Pengaruh penduduk mengurus rumah tangga, penduduk usia sekolah dan pendidikan terhadap tingkat partisipasi angkatan kerja perempuan adalah sebagai berikut: (a) Jumlah penduduk mengurus rumah tangga dan jumlah penduduk usia sekolah memiliki berpengaruh negatif secara signifikan terhadap TPAK perempuan 
yang artinya dapat menurunkan TPAK; (b) Variabel pendidikan memiliki hubungan positif terhadap TPAK perempuan tetapi tidak secara signifikan dan apabila dengan tingkat keyakinan $90 \%$ maka, pendidikan berpengaruh positif secara signifikan terhadap TPAK perempuan; (c) Faktor yang paling dominan yang mempengaruhi TPAK perempuan antar kabupaten di Provinsi Riau adalah jumlah penduduk mengurus rumah tangga.

Berdasarkan pembahasan yang telah dilakukan dan dikaitkan dengan kesimpulan yang telah didapat maka penulis mencoba memberikan saran sebagai berikut: (1) Angkatan kerja perempuan harus lebih meningkatkan perannya di segala sektor pembangunan sehingga tenaga kerja tidak hanya lebih layak bekerja di sektor informal tetapi harus dapat terjun di sektor formal dan dapat meningkatkan kualitas pendidikan dan skill agar dapat bersaing di pasar kerja; (2) Diharapkan kepada pemerintah agar dapat memperhatikan angkatan kerja baik laki-laki maupun perempuan agar mendapatkan pekerjaan dengan layak sesuai dengan kemapuan dan skill yang mereka miliki serta menyediakan sarana dan prasarana untuk dunia pendidikan dan penyuluhan untuk masyarakat yang kurang mampu, agar mereka mendapatkan hak yang sama dengan angkatan kerja lainnya.

\section{Daftar Pustaka}

Adioetomo, Moertiningsih, S. dan Samosir B. 2010. Dasar-Dasar Demografi. Salemba Empat. Jakarta.

Affandi, A. 2009. Analisis Faktor-faktor yang Mempengaruhi Perbandingan Tingkat Partisipasi Angkatan Kerja Laki-laki dan Perempuan di Kota Pekanbaru. University of Riau.

Arfida, B. 2003. Ekonomi Sumber Daya Manusia. Ghalia Indonesia. Jakarta.
Badan Pusat Statistik Riau. 2015. Riau Dalam Angka. Pekanbaru.

Baltagi, B. H. 2005. Economic Analysis of Panel Data. John Willey \& Sons. New York.

Cahaya, D. M. 2014. Faktor-faktor yang Mempengaruhi Tingkat Partisipasi Angkatan Kerja Wanita Muda Dalam Kegiatan Ekonomi Kota Makassar. University Hassanuddin.

Danim, Sudarwan, 2004, Ekonomi Sumberdaya Manusia, Lembaga Penerbit Pustaka Setia, Bandung.

Gujarati, D. 2004. Basic Econometric (4th ed.). Mc.Graw Hill companies. New York.

Herlina. 2014. Faktor-faktor yang Mempengaruhi Tingkat Partisipasi Angkatan Kerja Perempuan di Kabupaten Siak. Universitas Riau.

Hidayat, M. 2014. Inequality Across Districts and Cities in the Riau. Economic Journal of Emerging Markets, 6(2): 106-118. http://doi.org/10.20885/ejem. vol6.iss2.art4.

Martini, Dewi Putu. 2012. Partisipasi Tenaga Kerja Perempuan dalam Meningkatkan Pendapatan Keluarga. Jurnal Ekonomi Kuantitatif Terapan 5(2): 119.

Mulyadi. 2003. Ekonomi Sumber Daya Manusia. Rajawali Pers. Jakarta.

Riyadi, S. 2001. Faktor-faktor yang Mempengaruhi Tingkat Partisipasi Angkatan Kerja Wanita Daerah Tingkat 1 Jawa Barat. Universitas Diponegoro.

Simanjuntak, P. 2001. Pengantar Ekonomi Sumber Daya Manusia. FEUI Press. Jakarta.

Soewartoyo. 2005. Isu Ketenagakerjaan dan Pembagunanan Sumber Daya Manusia. PPK-LIPI. Jakarta. 
Suroto. 1992. Strategi Pembangunan dan Perencanaan Kesempatan Kerja. Gadjah Mada University Press. Yogyakarta.

Todaro, M. dan Smith, S. 2013. Pembangunan Ekonomi (11th ed.). Erlangga. Jakarta.

Undang-Undang RI No. 13 Tentang Ketenagakerjaan Tahun 2003 bab 1 Pasal 1 dan 28

Undang-Undang SISDIKNAS No. 20 tahun 2003. (n.d.).

Widarjono, A. 2013. Ekonometrika Pengantar dan Aplikasinya. UPP STIM YKPN. Yogyakarta. 